\title{
La reforma carolingia del clero secular y la renovación eclesial (siglos VIII-IX)
}

\author{
The Carolingian Reform of the Secular Clergy \\ and Ecclesial Renewal (8th-9th Centuries)
}

José ANTONIO CALVo GómEZ

Universidad Pontificia de Salamanca

ORCID: https://orcid.org/0000-0002-9483-6866 | jacalvogo@upsa.es

Fecha de recepción: 29/6/2021

Fecha de aceptación: 15/7/2021

https://doi.org/10.52039/seminarios.v66i228.444

RESUMEN: Este trabajo de investigación histórica trata de interpretar los proyectos de reforma del clero secular promovidos por los agentes del renacimiento carolingio durante los siglos VIII y IX. Pretende valorar algunas de las condiciones que se fueron vinculando a la vida y el ministerio de los clérigos en torno a la obra del arzobispo Crodegango de Metz ( $c a$. 702-766) y su aplicación en tiempos del emperador Carlomagno (768-814) y su hijo Ludovico Pío (814-840). Junto a las precisiones sobre la celebración de los sacramentos y el ejercicio de la cura animarum, cabe estudiar la emisión de la promesa de obediencia como parte fundamental de la ordenación sacerdotal y todo cuanto afecta a la digna sustentación de los ministros, en particular el concepto del beneficio eclesiástico.

PALABRAS ClAVE: Beneficio eclesiástico, Crodegango de Metz, obediencia clerical, Renacimiento Carolingio.

ABSTRACT: This work of historical research tries to interpret the projects of reform of the secular clergy promoted by the agents of the Carolingian Renaissance during the 8th and 9th centuries. It aims to assess some of the conditions that were linked to the life and ministry of the clergy around the work of Archbishop Crodegang of Metz (ca. 702-766) and its application in the time of Emperor Charlemagne (768814 ) and his son Ludovico Pio (814-840). Along with the details on the celebration of the sacraments and the exercise of the cura animarum, it is worth studying the issuance of the promise of obedience as a fundamental part of priestly ordination and everything that affect the worthy support of ministers, in particular the concept of ecclesiastical benefit.

KEYwords: Carolingian Renaissance, Clerical Obedience, Crodegang of Metz, Ecclesiastical Benefit. 


\section{INTRODUCCIÓN}

El renacimiento carolingio de los siglos VIII y IX estableció un modelo sacerdotal bien caracterizado en torno a cinco conceptos que, en su presentación unitaria, supusieron una cierta novedad en la Iglesia: la formación cultural, teológica, moral y litúrgica; la vida comunitaria del clero secular, según cierta regla de inspiración benedictina; la promesa de obediencia como clave de pertenencia a la jurisdicción del obispo diocesano; la celebración ex opere operato de los sacramentos, sobre todo de la eucaristía; y la garantía jurídica de la congrua sustentación, o el beneficio eclesiástico.

En un marco general de renovación y centralización de las instituciones del Estado del emperador Carlomagno, consagrado rey de los francos el año 768, la Iglesia pasó a formar parte del engranaje de actuación de los monarcas carolingios y puso sus mejores recursos y protagonistas al servicio de la nueva cristiandad, del Imperio cristiano que se prolongó, en una nueva fase, ahora germánica, hasta el tratado de Verdún del año $843^{1}$.

En línea con su padre, Pipino el Breve (754-768), que inauguró la dinastía carolingia y entregó al papa, el año 756, los territorios que luego conformarán los Estados Pontificios, Carlomagno promovió una política de apoyo y protección de la Sede Apostólica que culminó con la coronación del Emperador, en Roma, durante la navidad del año 800. Las consecuencias de esta profunda imbricación de las instituciones pronto se dejaron sentir en la vida y el ministerio de los clérigos seculares y de los monjes de los principales cenobios, sobre todo benedictinos.

El beato Alcuino de York ${ }^{2}$ (ca. 735-804), que rigió la Escuela Palatina de Aquisgrán desde el año 782, con el apoyo de san Paulino de Aquilea (ca. 726802) y del hispano visigodo san Teodulfo de Orleáns ( $c a .750-821)$, estableció un programa de formación cultural, teológica, moral y litúrgica para el clero que, el año 787, Carlomagno mandó implantar en todos sus territorios. Son conocidos los Homiliarios de Pablo Diácono (ca. 710-799) para la educación

1. D. Folliard, «La reforma carolingia: a la unidad por la uniformidad», Concilium. Revista internacional de Teología 164 (1981) 72-79; A. B. Sánchez Prieto, «Reorganización política, reforma religiosa, renacimiento cultural. El legado carolingio a la identidad de Europa», en: J. Peña González- M. A. Rodríguez de la Peña (eds.), Carlomagno y la civilización carolingia: Estudios conmemorativos en el 1200 aniversario (814-2014), Madrid 2014, 89-124.

2. J. J. Contreni, «Learning for God: Education in the Carolingian Age», The Journal of Medieval Latin 24 (2014) 89-129; M. A. Rodríguez de la Peña, «Alcuino de York, ideólogo del 'Imperium christianum': el análisis político en el Renacimiento Carolingio», en P. Sánchez Garrido- C. Martínez Sicluna y Sepúlveda, Historia del análisis político, Madrid 2011, 175-188; M. I. Solarana Cabezuela, «La escuela palatina de Aquisgrán: Alcuino de York», Revista de Arqueología 27/302 (2006) 47-55. 
de los clérigos; y el De ecclesiasticis officiis, libri quatuor, sobre la liturgia, de Amalario de Metz $^{3}$ (ca. 775-859), discípulo de Alcuino. El influjo de las escuelas carolingias se dejó sentir por todos los rincones del viejo continente, desde las riberas del Ebro, en la Marca Hispánica, hasta las lejanas tierras de la Marca Soraba, el viejo limes Sorabinus, en la cuenca del Elba ${ }^{4}$.

El sínodo de Aquisgrán del año 816 impulsó, en la jurisdicción imperial de Ludovico Pío, el programa definitivo para la unificación de la vida monástica y clerical en un marco general de centralización de todas las instituciones civiles y religiosas. Se impuso en todos los monasterios la regla de san Benito de Nursia (ca.480-547) según la versión interpolada de san Benito de Aniano (ca. 750-821), lo que en la práctica implicó la supresión del resto de disposiciones canónicas del ordo regularis ${ }^{5}$.

En esta misma asamblea de Aix-la-Chapelle, el clero secular consolidó su posición en la cura animarum y ocupó nuevos espacios eclesiales en capillas e iglesias propias ${ }^{6}$. Para todos los sacerdotes, singularmente para los miembros de los cabildos de las catedrales y colegiatas, este sínodo propuso, con menor aceptación, los estatutos que san Crodegango había redactado, hacia el año 754, para los canónigos de la catedral de Metz. La faceta más visible de esta legislación era la que afectaba a la residencia de los clérigos de las principales iglesias urbanas. Además, se redactaron otras disposiciones sobre la vinculación de los ministros sagrados a la jurisdicción diocesana,

3. A. García Macías, «Amalario de Metz (775-859)», Pastoral litúrgica: documentación información 318-319 (2010) 409-414; A. V. Ivorra Robla, Los sentidos de la liturgia en Amalario de Metz, León 2007; Id., «A propósito de la palabra según Amalario de Metz», Toletana. Cuestiones de Teología e Historia 19 (2008) 75-87.

4. F. Miranda García, «Autores carolingios en los códices hispanos (siglos IX-XI). Un ensayo de interpretación», Studia historica. Historia medieval 33 (2015) 25-50. En esta misma escuela ejercieron otros profesores como san Rabano Mauro (ca.779-856), autor de la obra De institutione clericorum (819) de notable influencia posterior. Véase O. M. Phelan, «New Insights, Old Texts. Clerical Formation and the Carolingian Renewal in Hrabanus Maurus», Traditio: Studies in Ancient and Medieval History, Thought, and Religion 71 (2016) 63-89; A. B. Sánchez Prieto, «Rabano Mauro, Sobre la educación de los clérigos (De institutione clericorum): alcance y penetración de la escuela carolingia», Anuario de Historia de la Iglesia 24 (2015) 488-496; Id., "The Transmission and Reception of the De institutione clericorum», Millars: Espai i Historia 46/1 (2019) 17-40. Resultan muy conocidos los debates eucarísticos con san Pascasio Radberto (ca. 792-865) y Ratramno de Corbil (†870). Como reacción, muchos teólogos posteriores ahondaron en la formulación teológica sobre la presencia real de Cristo en la eucaristía.

5. G. Constable, Monks, Hermits and Crusaders in Medieval Europe, London 1988.

6. V. Bo, Storia della parrochia. I secoli dell'infanzia (sec. VI-XI), Roma 1990, 107-109; J. A. Calvo Gómez, La vida común del clero medieval. Origen y expansión de los canónigos regulares, Madrid 2016, 192-201; E. Mitre Fernández, Una primera Europa. Romanos, cristianos y germanos (400-1000), Madrid 2009, 160-162. 
la congrua sustentación del clero y la celebración de los sacramentos, en particular de la eucaristía pro vivis et defunctis, de profundas consecuencias para la cura animarum en el Imperio Carolingio, sobre todo cuando se consumó su fragmentación después de la guerra civil (840-843) entre los hijos de Ludovico Pío ${ }^{7}$.

\section{La propuesta de san Crodegango para el Clero y la Regla de} AQUISGRÁN

Crodegango ( $c a .702-766$ ), obispo de Metz, fue el protagonista de la renovación de la vida del clero secular durante la reforma carolingia. La regla que, el año 754, redactó para los canónigos de su catedral fue parcialmente integrada en los decretos del sínodo de Aquisgrán del 816. Esta recepción contribuyó a que su propuesta de vida común del clero se extendiera por toda Europa y fuera asumida con cierto entusiasmo por la mayoría de los cabildos seculares de catedrales y colegiatas ${ }^{8}$.

\section{a) La Regla de san Crodegango de Metz del 754}

Crodegango, hijo de una noble familia de la Corte de los francos, nació a principios del siglo VIII en el valle del Mosa, en el antiguo condado de Hesbaye, hoy entre Bélgica y los Países Bajos. Su educación junto al mayordomo de palacio y su fidelidad en la lucha a su protector hicieron que, tras la consolidación definitiva de Carlos Martel después del 715, fuera nombrado canciller para la gestión de los intereses del reino.

La victoria contra los musulmanes de Al Ándalus en la batalla de Poitiers del 732 fortaleció la reputación de Carlos Martel entre sus seguidores. Esta empresa suprimió cualquier intento de deslegitimación del hijo de Pipino de Heristal y de una concubina de la corte de Teoderico III, rey nominal de los francos, y aseguró el prestigio de Crodegango, su fiel secretario. El año 742,

7. J. del Hoyo Calleja- B. Gazapo Andrade, Anales del Imperio Carolingio (800-843), Madrid 1997. Para una interpretación general de este periodo, ver: S. Claramunt- E. PortelaM. González- E. Mitre, Historia de la Edad Media, Barcelona 2010; R. Collins, La Europa de la Alta Edad Media, 300-1000, Madrid 2000; J. A. García de Cortázar y Ruiz de Aguirre, Historia general de la Alta Edad Media, Madrid 1984; J. Dhondt, La Alta Edad Media, Madrid 1993; I. Montanelli, Historia de la Edad Media, Barcelona 2004; J. M. Nieto Soria (coord.), Europa en la Edad Media, Madrid 2006; J. Valdeón Baruque, La Alta Edad Media, Madrid 2005.

8. V. Bo, Storia della parrochia..., 83-142; J. A. Calvo Gómez, El clero y los religiosos en la Edad Media, Madrid 2017, 159-185. 
al morir Carlos Martel, fue nombrado obispo de Metz, capital del reino de Austrasia hasta el destronamiento de Childerico III a manos del hijo de Martel el año 751. Las responsabilidades de san Crodegango en la Corte de Pipino el Breve, rey de los francos desde aquel mismo año hasta su muerte, el año 768 , no fueron menores 9 .

El 754, tras el martirio de san Bonifacio, el papa Esteban II confirió el palio de arzobispo a san Crodegango, quien no cejó en su empeño de reorganización de la Iglesia franca y de renovación del clero. Aquel mismo año compuso, para los ministros sagrados de su catedral, la regula canonicorum, que se benefició de la influencia política y eclesial de su autor para extenderse a otras comunidades seculares de catedrales y colegiatas ${ }^{10}$.

La regla de san Crodegango del año 754 para el clero de la catedral de Metz se iniciaba con un prólogo en el que recriminaba los sacerdotes el incumplimiento de sus obligaciones canónicas ${ }^{11}$. Estas disposiciones, añadió, no hubieran sido necesarias si los pastores y el pueblo hubieran desempeñado sus deberes con diligencia. Se trataba de la primera regla canónica para el clero secular. En ella, frente a la ascendencia que venía tomando la tradición oriental en Occidente, se desarrollaba un programa de vida sacerdotal, litúrgica y cotidiana; y, bajo la influencia de la regla de san Benito, se proponía la acogida en el reino de los francos de las costumbres romanas, sin despreciar la tradición de la antigua liturgia galicana.

9. Pipino el Breve contó, en su consolidación definitiva en el trono de los francos, con el apoyo definitivo del papa Zacarías (741-752), quien determinó que debía ser rey el que ejerciera en realidad el poder. Después de la renuncia de Childerico III, el rey envió a Crodegango para que acompañara al papa Esteban II (752-757), amenazado por los lombardos, hasta Ponthion. Aquel viaje terminó con la Donación Carisíaca que, en la práctica, supuso el surgimiento de los Estados Pontificios sobre los territorios conquistados a los lombardos en Rávena y la Pentápolis. Véase J. A. García de Cortázar y Ruiz de Aguirre, Historia religiosa del Occidente medieval (Años 313-1464), Madrid 2012.

10. Años atrás, en el 747, al principio de su ministerio episcopal en Metz, Crodegango había fundado un monasterio en Gorze, bajo la regla de san Benito. Por influencia del arzobispo san Bonifacio (672-754), el gran apóstol de Alemania y fundador del monasterio de Fulda, el obispo de Metz inició en Fritzilar una cierta vida común del clero y, con el apoyo decidido de Pipino el Breve, determinó emprender su reforma y, en general, la de todas las instituciones de la Iglesia. Véase J. B. Pelt, Études sur la cathédrale de Metz I. La liturgie, Metz 1937.

11. F. Foschi, «La regula canonicorum di Crodegango di Metz: alcuni problemi linguistici e di metodo», en: C. Arias Abellán (ed.), Latin vulgaire-latin tardif VII: Actes du VII Colloque international sur le latin vulgaire et tardif, (Sevilla, 2-6 septembre, 2003), Sevilla 2006, 273-284; Id., «La formularità della lingua di Crodegango di Metz (742-766) e dei documenti del suo tempo», en: R. Wright, Latin vulgaire-latin tardif VIII. Actes du VIII Colloque international sur le latin vulgaire et tardif, Oxford, 6-9 septembre, 2006, Hildelheim 2008, 482-491. 
Crodegango estableció algunas claves para la vida del clero de Metz al que le impuso un proyecto riguroso de ayuno y clausura. Sin embargo, fue flexible en las exigencias vinculadas a la propiedad. Los ministros de la catedral entregarían sus bienes inmuebles, reteniendo el usufructo; pero podrían conservar sin reserva los bienes muebles. El modelo fundamental era la vita apostolica y la comunidad de los Hechos de los Apóstoles, pero interpretada con cierta flexibilidad por la flaqueza de los tiempos.

Para los que, verdaderamente imbuidos del espíritu de la reforma, fueran capaces de dar un paso más en la renuncia de sus bienes, Crodegango permitió que pudieran hacerlo en favor de la Iglesia, que administraría sus propiedades y garantizaría su sustento. Para todos estableció la vida común, con refectorio y dormitorio comunitario, los tiempos de silencio en clausura y ciertas actividades manuales, aunque siempre limitadas y condicionadas a la referida vita apostolica ${ }^{12}$.

San Crodegango murió en su diócesis el 6 de marzo del 766 después de una vida verdaderamente frenética de reforma y apostolado. Con el ascenso de Carlomagno (768-814), su obra no perdió actualidad. Al contrario, la pretensión unificadora del Emperador en todos los órdenes encontró en la disciplina de san Crodegango un recurso importante para la administración del clero secular del Imperio. Carlomagno luchó contra los derechos de sus sobrinos por la unidad del territorio; estableció el cristianismo como religión única, a veces a pesar de la resistencia civil, como en el caso de los sajones; eliminó la disparidad de reglas monásticas instaurando en todos los cenobios occidenta-

12. Se conocen cuatro adaptaciones de la misma regla. La regla genuina o primera, escrita por san Crodegango para los canónigos de la catedral de Metz el año 754, estaba compuesta por 23 capítulos. La versión ampliada de san Angilramno, sucesor de san Crodegango como arzobispo de Metz, que murió el año 791, añadió algunos detalles poco relevantes. La versión generalizada suprimió cualquier referencia al cabildo de Metz en orden a su aplicación en otras comunidades de clérigos seculares. En realidad, se podría hablar mejor de versiones generalizadas porque, según los casos, fueron suprimidos o añadidos algunos capítulos fundamentales. La versión interpolada, con 84 capítulos, se redactó a finales del siglo IX o a principios del X y, por tanto, posterior a la regla que se aprobó en Aquisgrán el año 816, de la que tomó varios títulos. Esta regla fue publicada originariamente en J. E. Migne, Patrologiae cursus completus, serie latina, 221 vols. (en adelante: PL) París 1844-1864, vol. 89, 1097-1120 (versión ampliada) y 1057-1096 (versión interpolada), aunque luego ha tenido numerosas ediciones. En cualquiera de sus versiones, en distinto grado e intensidad, llegó a transformar la vida de muchas comunidades de clérigos seculares y, sobre todo, sustituyó a la mayoría de las colecciones canónicas de las catedrales del Occidente europeo. Una de las llamadas versiones generalizadas, de 80 capítulos, estableció nuevas disposiciones en cuanto a la renuncia material de los bienes y permitió, incluso, la retención integral de los bienes inmuebles. Véase C. Giroud, L'ordre des chanoines réguliers de saint-Augustin et ses diverses formes de régime interne. Essai de synthèse historico-juridique, Martigny 1961, 83-99. 
les la regula monachorum de san Benito; e implantó la liturgia romana como propia. En este mismo sentido, esgrimió la regla de san Crodegango para el clero secular, que obligaba a la vida común, y trató de unificar la legislación de un estado autónomo por naturaleza. La pretensión carolingia encontró, en esta aspiración, dificultades casi insalvables al tratar de establecer la disciplina comunitaria a un clero ordenado para la vita apostolica que reclamaba cierta independencia.

El proyecto carolingio para el clero, que recogieron con frecuencia los sínodos y capitulares, encontró buena acogida entre los canónigos de las colegiatas y catedrales del Imperio. Sin embargo, la aplicación de la vita canonica a todos los clérigos seculares no llegó a consolidarse durante los reinados de Pipino el Breve (751-768) y Carlomagno (768-814). Todavía los sínodos de Maguncia y de Tours del 813, pocos meses antes de la muerte del Emperador, insistieron en una idea unificadora que solo encontró buena acogida entre aquellos que abandonaban, por fervor, las instituciones tradicionales de la Iglesia $^{13}$. El ascenso al trono de su hijo Ludovico Pío en enero del 814 permitió una nueva consideración de la unidad disciplinaria del clero franco.

\section{b) El sínodo y la regla canonical de Aquisgrán del 816}

Ludovico Pío (814-840) heredó un Imperio unificado, pero en peligro de deconstrucción. Además, la imbricación de los asuntos del reino y de la iglesia carolingia provocó que la inestabilidad del final del reinado de Carlomagno afectara a la consolidación que, después de las sucesivas abjuraciones reales de los principios arrianos y de la conversión de los distintos pueblos germánicos, se había logrado en las estructuras eclesiales de la Alta Edad Media durante los siglos VII y VIII.

El Emperador suprimió, por decreto, todos los privilegios de las iglesias y, en un intento por recomponer la unidad administrativa de todos los espacios eclesiales, convocó el sínodo de Aquisgrán, que se celebró en la capital imperial el año 816. Junto a las disposiciones de san Benito de Aniano para los monjes, ratificadas en la gran asamblea de todos los abades del Imperio del año siguiente, el concilio de Aquisgrán estableció una regla para los clérigos. Esta doble regulación, en la práctica, representaba la primera división clara entre el ordo regularis, de los monjes, y el ordo secularis, de los clérigos seculares, en particular de los canónigos de catedrales y colegiatas y, por extensión, de los clérigos parroquiales con cura de almas.

13. L. Halphen, Charlemagne et l'Empire Carolingen, Paris 1947. 
La regula canonicorum de Aquisgrán, o regla imperial, del año 816, estaba compuesta por 144 capítulos que, en su mayor parte, recogían la doctrina de los Santos Padres y de los concilios de la Antigüedad y el Alto Medievo. Después del número 114 de esta normativa, se integraron algunos aspectos significativos de reforma procedentes sobre todo de la regla de san Crodegango. En concreto, el capítulo 115 establecía que los canónigos también estaban llamados a la perfección evangélica, como los monjes, aunque no se les exigiera, como a estos, una vida tan austera y la renuncia a sus bienes ${ }^{14}$.

La prioridad de los canónigos, según Aquisgrán, debía ser la oración pública y común; sin mencionar expresamente la actividad apostólica, propia del clero secular. Ludovico Pío, al exigir a los cabildos, colegiales y catedralicios, la prelación litúrgica, les entregó también medios materiales para poder cumplir su misión ${ }^{15}$. Sin embargo, al religar a un segundo plano la vita apostolica, dio ocasión a que muchas comunidades de canónigos aquisgranenses abandonaran el ministerio pastoral hasta el punto en que, junto a ciertas catedrales y colegiatas, se tuvieran que erigir parroquias, dependientes de estas, para que aseguraran las funciones propias de la cura animarum, catequéticas y sacramentales ${ }^{16}$.

14. PL 105, 816-934. J. R. Palanque, De Constantino a Carlomagno. A través del caos bárbaro, Andorra 1961, 124-125, analiza la figura de san Bonifacio, que «ejerció una influencia más profunda, menos anárquica, gracias al apoyo conjugado del papa y del mayordomo de Palacio. De 742 a 747 preside en calidad de legado pontificio varios concilios en Austrasia y en Neustria, donde se promulgaron decisiones capitales: obligación del celibato, de residencia, de conducta digna y edificante para los sacerdotes y los obispos; sanciones rigurosas para los que contravinieran y los monjes o clérigos errantes; institución de exámenes para los candidatos a la ordenación y para los sacerdotes de las parroquias en ocasión de las visitas pastorales y de los sínodos diocesanos; prohibición de las prácticas supersticiosas y de los matrimonios consanguíneos». El autor reconoce que después de la muerte de san Bonifacio estas decisiones quedaron como letra muerta. Habrá que esperar a los capitulares de Carlomagno y a las asambleas reunidas bajo su alta dirección para que se haga efectiva su obra reformadora. Será el momento de la restauración de las circunscripciones metropolitanas bajo el gobierno de los arzobispos, cuya nomenclatura se desarrolla en este momento, sometidos a la vigilancia de la Corte, que se reserva el nombramiento de todos los prelados. Los sacerdotes deberán dar razón de sus conocimientos y de una cierta capacidad para la predicación en lengua vernácula. «En las ciudades deben vivir en comunidad para observar mejor sus obligaciones morales y espirituales; la regla de Crodegango de Mets se difunde por Austrasia, y el concilio de Aix-la-Chapelle de 817 impone una regla semejante en todo el Imperio. Cada obispado tendrá, desde entonces, un cabildo canonical».

15. S. Kotzula, Der Priesterrat. Ekklesiologische Prinzipien und kanonistische Verwirklichung, Leipzig 1983, 45-53.

16. Algunas asambleas sinodales del siglo IX, ante el abandono de las funciones parroquiales de las colegiatas, exigieron a los canónigos la creación de centros hospitalarios en los que atender las necesidades de pobres, enfermos y peregrinos. Los sínodos de París del 829; Aquisgrán, 836; Meaux, 843; Maguncia, 847; y Soissons, auspiciados por Ludovico Pío y sus hijos, exigieron el cumplimiento de los decretos de Aquisgrán, que encontraron numerosas 
Después de la muerte de Ludovico Pío, el año 840, casi todos los cabildos de Occidente habían aceptado la regla, incluidos la Seo de Urgel, Gerona y Barcelona, en la Península Ibérica. La decadencia y división del reino franco provocó, de nuevo, la desnaturalización de la vida canónica promovida por la reforma carolingia. La crisis de la Iglesia de finales del siglo IX y buena parte del X, se tradujo, también, en una larga agonía de los cabildos seculares y los monasterios benedictinos. La recuperación que experimentó el monacato después de la fundación del Cluny, el 11 de septiembre del año 909, no se logró en la vida canonical hasta mediados del siglo $\mathrm{XI}^{17}$.

\section{EL CONCEPTO DE OBEDIENCIA DE LOS CLÉRIGOS SEGÚN LA DISCIPLINA CAROLINGIA}

En la Alta Edad Media, el concepto de obediencia evolucionó a medida que las comunidades se fueron desarrollando. Existió una base constitucional relativa al desarrollo de la jerarquía y a la subordinación de unos clérigos a otros según los grados de esta misma jerarquía. Los autores carolingios debatieron con profundidad sobre el concepto de la obediencia, las condiciones que debía cumplir el mandato o la norma para que obligara a su cumplimiento, y los cauces y límites de la autoridad, que siempre debía estar sometida a un orden interno más o menos explícito. El obispo de Roma sostuvo el primado de jurisdicción universal y ordinaria sobre cada uno de los demás obispos y fieles ${ }^{18}$; los obispos, al frente de sus diócesis, gobernaron los territorios y las personas con potestad ordinaria e inmediata ${ }^{19}$.

resistencias entre los clérigos locales. Muchos cabildos de las grandes catedrales, así como miles de comunidades de canónigos seculares del Imperio y de los territorios del Occidente europeo, por fervor, aceptaron con satisfacción la regla y, por tanto, la vida común de los canónigos. Se conocen los casos de vida común en Vienne y Reims, después del 814; Limoges, en el 817; Tournai, en el 818; y Auxerre, en el 819; que tuvieron como continuadores los cabildos de Paderborn, el 822; Langres, el 834; y Mans, el 835.

17. Los autores de la reforma gregoriana, después del sínodo de Roma del 1059, vieron en la regla de Aquisgrán contradicciones importantes entre el proyecto ideal de la vita vere apostolica que compartían los apóstoles en el libro de los Hechos y la normativa sinodal que autorizaba el uso personal y la retención de bienes a los canónigos de catedrales y colegiatas seculares. La regla de san Crodegango solo había autorizado la posesión de bienes muebles, usando de los inmuebles durante su vida. La autorización de Aquisgrán de retener también los bienes inmuebles como propios llevaba, en la práctica, siempre según los promotores de la reforma gregoriana, a la relajación canonical.

18. C. Ayala Martínez, El pontificado en la Edad Media, Madrid 2016; J. O’Malley, Historia de los papas. Desde Pedro hasta hoy, Santander 2011.

19. R. Arnau-García, Orden y ministerios, Madrid 1995; P. F. Fransen (ed.), Authority in the Church, Leuven 1983. E. Mitre Fernández, La Iglesia en la Edad Media, Madrid 2003. 
También se analizó la figura jurídica del sacerdote y su obligación de adscribirse a una diócesis o a una orden monástica. Los reformadores carolingios condenaron a los clérigos vagos y las llamadas ordenaciones absolutas, que eximían de la obediencia debida a su ordinario. La ordenación al servicio de una diócesis y los juramentos anejos que se elaboraron para su correspondiente fijación jurídica crearon, de hecho, un nuevo título de obediencia en el clero secular ${ }^{20}$.

\section{a) La «adscriptio» de los clérigos seculares a una iglesia diocesana}

La paulatina organización jerárquica de la Iglesia durante la etapa carolingia hizo necesario el fortalecimiento del concepto de obediencia. Esta actuación, ahora remarcada, había tenido su origen siglos atrás. La disciplina eclesiástica urgió a los clérigos a proferir cierto compromiso, ya desde los primeros siglos del cristianismo, con el propósito de garantizar la necesaria estabilidad de la iglesia local y de la comunión entre las iglesias ${ }^{21}$. El XI concilio de Toledo, del año 675, insistió en el concepto de la obediencia. Desde aquella fecha, en la Hispania visigoda no se ordenó a ningún sacerdote que no hubiera hecho antes promesa de obediencia al prelado ${ }^{22}$.

20. La obediencia era deber del subordinado y exigía a todos los clérigos, singularmente a los presbíteros, la reverencia a su ordinario, normalmente el obispo o, en las órdenes religiosas clericales, el superior monástico o conventual. Las disposiciones que acompañaban los cánones sobre la obediencia señalaban, con detalle, las penas para los que cometieran delito de desobediencia al romano pontífice o al ordinario propio, y para los que conspiraran contra su autoridad. Véase S. Kotzula, Der Priesterrat ..., 7-44. Según la tradición canónica, la principal concreción de la obediencia estaba en la aceptación y cumplimiento fiel del cargo que el ordinario le encargaba al clérigo. Con las regulaciones bajomedievales de los beneficios, sobre todo después de la etapa de Aviñón, la provisión de los cargos, en función de distintos modos de oposición, retiró de las manos de los obispos muchas de sus competencias. Véase T. Rincón-Pérez, El orden de los clérigos o ministros sagrados, Pamplona 2009.

21. La tradición patrística, desde san Ignacio de Antioquía, fue delimitando los rasgos de la obediencia debida a Dios y a la legítima jerarquía de la Iglesia. El surgimiento de los primeros movimientos heterodoxos y, en particular, con la crisis arriana a partir del siglo IV, la exigencia de la obediencia estuvo condicionada, sobre todo, a la fidelidad a la tradición nicena y a la amenaza permanente de ruptura de la comunión. Mansi (1692-1769), en su obra sobre los concilios, recogió algunos textos de los canones Apostolorum recibidos en el sínodo de Trullo del año 692 en una tradición que procedía del siglo IV. En el canon 38 se indicaba: «Presbyteri et diaconi absque voluntate episcopi nihil peragunto; ipsius enim fidei populus Domini commissus est, et pro eorum animabus ab ipso repetetur ratio». En el mismo sentido se pronunció el concilio de Calcedonia del año 451; nada sin el permiso del obispo, por el bien de las almas. Véase G. D. Mansi, Sacrorum comciliorum nova et amplisima collectio, 31 vols. Florencia-Venecia 1759-1798; A. Baron- H. Pietras (eds.), Acta synodalia. Documentos sinodales desde el año 50 hasta el 381, Madrid 2016.

22. El canon 10 prescribía: «Regulis canonicis atque mandatis suorum praelatorum obedientiam exhibitorum esse sollemniter sponderet». Durante los siglos II y III, la materia 
Puesto que la obediencia guardó una estrecha relación con el concepto de adscriptio o incardinación, la evolución histórica de esta motivó la variación de aquella. El principio fundamental del concilio germánico de abril del 742 para la reforma del clero era muy simple: «Que cada sacerdote residente en un obispado esté sometido al obispo de la diócesis en la cual se encuentra $»^{23}$.

Se imponía, por tanto, el régimen territorial romano frente al modelo insular o étnico. Este concilio designó muchos obispos y determinó algunos monasterios como sedes con jurisdicción ordinaria sobre los territorios. San Bonifacio fue reconocido como arzobispo o missus, delegado del papa, con autoridad sobre los obispos de su circunscripción metropolitana. En la práctica, el título de arzobispo lo ostentaba aquel que era capaz, en nombre del papa, de proseguir la reforma. A la muerte de san Bonifacio, san Crodegango, obispo de Metz, le sucederá en esta función de arzobispo y convocará una serie de sínodos de reforma entre el 756 y el 762. Poco a poco se reestablecerá esta estructura cuyo origen, con cierta distancia, se situaba en las circunscripciones provinciales de Roma.

La renovación encontró acomodo, según venimos exponiendo, durante el reinado de Ludovico Pío. La restauración cultural había empezado a germinar. Las diversas asambleas diocesanas dieron sus frutos. Muchos estatutos fueron redactados por los obispos Teodulfo de Orleáns y Wulfade de Bourges, que trataron de mantener al clero alejado de las tentaciones del mundo. Las diversas regulaciones fueron recibidas como propias en los territorios. En ellas se atendió a la administración sacramental y la predicación, a las fiestas; pero también a la formación del clero y a sus deberes de residencia.

Los concilios de Aix-la-Chapelle del 816 y 817, además de establecer la regla de san Benito como exclusiva para los monasterios carolingios, llevó al límite la uniformidad en el clero secular. A partir de este momento, las jurisdicciones metropolitanas, bajo el gobierno de un arzobispo, alcanzaron a todo el territorio. Los obispos ordenaban la vida de los clérigos. Se impuso, asimismo, la uniformidad en la recepción de los sacramentos y la moral personal y comunitaria. La transformación de la estructura eclesial, en la etapa

sobre la obediencia no fue un concepto discutido. El ministerio apostólico dependía directamente de la adscriptio en la clericatura de una Iglesia concreta. El servicio estaba centrado en la asistencia a las plegarias públicas y en la colaboración con el ministerio de los obispos. A cambio de aquel servicio, el clérigo tenía asegurado el sustento en el reparto de la mesa común. Así se pronunciaron los Padres del concilio de Toledo del 398; y los asistentes al sínodo de Agde del 506.

23. J. Paul, El cristianismo occidental en la Edad Media. Siglos IV-XV, Valencia 2014. 
carolingia, desde finales del siglo VIII, conllevó por tanto la renovación del concepto de incardinación. Las consecuencias, todavía solo apuntadas, de la pérdida de la relación del ministro con la comunidad celebrante vendrían a contradecir, paradójicamente, las pretensiones de renovación del clero secular. La ordenación a título de patrimonio fue solo una de estas consecuencias no buscadas por los reformadores. Pero, en la imbricación con la fragmentación feudal de los siglos IX y X, desmontó, en muy poco tiempo, todo el trabajo realizado.

\section{b) La ordenación a título de patrimonio}

Frente a las pretensiones de los reformadores de finales del siglo VIII, la relación de los clérigos con la jerarquía local se rompió a causa de la exigencia de incardinación sin referencia a la comunidad celebrante y, sobre todo, de la señorialización del terrazgo y la feudalización de la sociedad después del tratado de Verdún del 843. Algunos sacerdotes ejercieron su ministerio al servicio de diferentes señores y, en muchos casos, paradójicamente, quedaron desligados de la obediencia debida a su obispo diocesano, al que solo acudían para recibir la ordenación y la consagración de los oleos ${ }^{24}$.

Los sínodos, en general, condenaron esta actuación, que desviaba el proyecto evangélico de servicio a la comunidad. El rechazo a esta forma de ordenación, que se generalizó en el Imperio Carolingio, vino condicionado también porque, al retirar de la jurisdicción ordinaria a muchos sacerdotes, las iglesias parroquiales quedaron desatendidas, sin pastores que las rigieran.

A partir del siglo IX, se generalizaron las ordenaciones absolutas que, a partir del XII, se regularon canónicamente al considerar que el presbítero recibía el ministerio sacerdotal titulus patromonii, a título de patrimonio. En estas ordenaciones, el presbítero aseguraba tener medios para poderse sustentar, con la garantía de que pasaría inmediatamente a la dependencia de un señor, a veces de su propia familia. También, en esta segunda causa de relajamiento, el clérigo quedaba liberado de la obligación de servir a la diócesis ya que los canonistas sostenían que un sacerdote ordenado bajo la garantía de su patrimonio personal no estaba obligado a colaborar con el obispo en el servicio de una iglesia local, aunque mantendría la obligación de recitar el oficio divino.

24. La teología sobre el sacerdocio, que dignificaba en sí su condición, en relación sobre todo con la eucaristía, de la que se convertía en propietario, rompía de facto con la necesaria relación pro eis con la comunidad celebrante de la Iglesia primitiva. 
4. LA CONGRUA SUSTENTACIÓN DEL CLERO, LOS BENEFICIOS Y LAS CAPELLANÍAS

Uno de los rasgos que condicionó la existencia del clero después del siglo VIII fue la posibilidad de contar con una digna sustentación cuyo instrumento fundamental fue el beneficio, asociado al oficio o cargas piadosas que debía cumplir el ministro ${ }^{25}$. Entre los beneficios, destacaron las capellanías. En último término, la reforma carolingia, por la peculiar relación que se estableció entre la Iglesia y los poderes de territorio, inmersos en un proceso de feudalización, ruralización y, por tanto, de fragmentación jurisdiccional, dejó establecidos algunos nichos ministeriales que asumieron como propios $\mathrm{y}$, durante los siglos IX y X, no presentaron particulares dificultades eclesiológicas ${ }^{26}$.

\section{a) Delimitación teórica del concepto de beneficio eclesiástico a partir del siglo VIII}

El beneficio eclesiástico fue la clave para la manutención del clero secular después de la reforma carolingia. Podría definirse como una entidad jurídica, persona moral no colegiada, constituida a perpetuidad por la autoridad eclesiástica competente, conformada mediante un oficio sagrado y el derecho asociado a percibir las rentas anejas por la dotación de este oficio, también llamada prebenda ${ }^{27}$.

Este oficio, según la naturaleza del beneficio, podía estar dotado por bienes raíces; prestaciones personales o morales; ofrendas de los fieles; derechos de estola y altar, fijados por ciertos aranceles públicos o por la costumbre del lugar; o por distribuciones cotidianas o extraordinarias de las mesas capitulares o colegiales. El beneficiario de estas rentas adquiría, con ellas, las obligaciones propias del oficio al que se vinculaban por mandas piadosas o por disposiciones de la autoridad eclesiástica. A la vez, participaba, en

25. V. Bo, Storia della parrochia ..., 18-19. 70-72; P. Contamine, La economía medieval, Madrid 2000.

26. A mediados del siglo XI, sin embargo, la ruptura con el orden primitivo de la Iglesia resultaba tan evidente que los protagonistas de la renovación gregoriana se emplearon a fondo para contrarrestar sus efectos, condenados expresamente en los sínodos y concilios de reforma. La situación se volvió insostenible sobre todo en las pequeñas comunidades rurales. Véase P. Bonnassie, Le clergé rural dans l'Europe médiévale et moderne, Toulouse 1995; J. Gaudemet, «La vie paroisseale en Occident au Moyen Âge et dans les temps modernes, en les communautés rurales», Recueils de la Société Jean Bodin 43 (1984) 64-86.

27. M. Teruel Gregorio de Tejada, Vocabulario básico de Historia de la Iglesia, Barcelona 1993, 19-30. 
cierto grado, de la jurisdicción aneja, de orden o jurisdicción, según el derecho canónico. La ruptura con la tradición de la iglesia primitiva fue clara después del $816^{28}$.

En ciertos casos, los beneficios formaban parte del derecho común, sujetos a la autoridad ordinaria de los obispos, que gozaban de la libre disposición. Pero, en muchos oficios, de patronato, era la corporación o el patrono los que tenían derecho de presentación. En algunas capellanías, el fundador solía poner algunas condiciones, como la preferencia por clérigos de la propia familia o de la ciudad natal. En otros momentos, se confirmaron ciertos abusos como la colación de ciertos oficios en personas a las que se les obligaba, sin complemento beneficial, a atender a nuevas cargas no previstas en la fundación, como la celebración de ciertas misas en sufragio de nuevos difuntos o atender tareas educativas a los hijos de los patronos sin que de ello resultase un incremento del neto recibido.

Siempre se presuponía la idoneidad personal y canónica del candidato, que aseguraba el ordinario ${ }^{29}$, aunque la tipología de los beneficios varió durante la Edad Media. Fundamentalmente estos fueron de dos tipos: los beneficios curados, con cura de almas; y los simples, normalmente debidos a obligaciones piadosas, llamados simples servideros cuando atendían cargas

28. Según el derecho, el acceso al oficio y, por tanto, al beneficio, se hacía mediante la provisión canónica o la colación en propiedad, no solo en administración. Los pasos del proceso eran la designación o presentación del candidato, la colación o institución del título, la institución personal y la toma de posesión o investidura. Esta podía ejecutarse por la autoridad civil, al igual que la presentación del candidato a cubrir la plaza vacante. Existieron diversos modos para la provisión: la libre colación, en la que podía intervenir, también, la recomendación o el concurso; la institución, cuando precedía una presentación o nombramiento por parte del que ostentara el derecho de patronato, como el rey o ciertos señores seculares; la confirmación, si precedía una elección simple para un puesto, como el pontificado, o se producía cierto escrutinio; la admisión, si había precedido la postulación y la dispensa de ciertos impedimentos; y la elección colativa junto a la aceptación del candidato, como en el mismo pontificado o en los superiores religiosos, si la votación no exigía la confirmación. La pérdida del beneficio podía producirse por renuncia, que a la vez podía ser expresa o tácita, absoluta o condicionada; por privación directa o judicial, administrativa o económica, llamada remoción, o disciplinar, llamada destitución; por traslación, voluntaria o judicial, administrativa o simple, que se ejecutaba y, por tanto, dejaba vacante el beneficio, cuando se tomaba posesión del nuevo oficio; $y$, también, por la finalización del tiempo fijado en el nombramiento.

29. A finales del siglo $\mathrm{XV}$, en algunos beneficios, como en los de las catedrales, se impuso el estatuto de limpieza de sangre e, incluso, el impedimento para la provisión en extranjeros, lo que se salvó mediante la redacción de cartas de naturaleza que les vinculaban a la Corona. Solo de obviaba este reconocimiento cuando el papa verificaba una provisión que, si la hacía en consistorio, recibía el nombre de preconización. Además, se exigía la clericatura, según los grados. Por ejemplo, si un beneficio llevaba asociada la cura de almas, se exigía al candidato la ordenación de misa también llamada de altar o presbiteral. 
de tipo cultual. Cuando los beneficios se erigían para un servicio de toda la iglesia, como una parroquia o una diócesis, eran considerados propios; mientras que los impropios respondían a intereses particulares ${ }^{30}$.

Dentro de la tipología de los beneficios eclesiásticos, se distinguieron en función de la institución en la que se ejercían los oficios. Hubo beneficios capitulares vinculados a una catedral; los colegiales estaban vinculados a una colegiata; los parroquiales, a una iglesia parroquial; y los patrimoniales, normalmente de capellanías, se ejercían en el ámbito de ciertos patronatos laicos. También se distinguió entre los beneficios consistoriales, si fueron provistos en consistorio, como la mayoría de las diócesis y algunas abadías; y los no consistoriales, provistos por otras vías. Si exigieron residencia, fueron residenciales; $y$, si no la exigían, fueron sencillos o no residenciales.

Junto a ellos, se erigió un conjunto muy abundante de oficios propios, asimilados a los beneficios, como fueron las vicarías parroquiales, las capellanías, las coadjutorías, las pensiones y las encomiendas temporales, entre otros. Muchos de estos oficios y beneficios pudieron llegar a unirse o servirse por la misma persona, según diversos mecanismos: por la vía extintiva, en la que varios beneficios desaparecían y se integraban en uno mayor que los englobaba; según el modelo aeque principalis, donde se unían en una persona, pero mantenía, cada uno, sus propiedades y derechos; o por el recurso minus principalis, en el que unos se subordinaban a otros, sin perder tampoco sus características. También pudieron llegar a dividirse por desmembración, traslación, conversión o supresión, aunque esto fue menos habitual.

La misma delimitación conceptual ya nos indica que la relación con la comunidad, constitutiva del ministerio en la época anterior, se rompió después de las asambleas de Aix-la-Chapelle del 816 y 817. La reforma carolingia, en su intento por garantizar la congrua sustentación del clero, lo introdujo en una dinámica de apetencia beneficial que encontrará duras embestidas morales y canónicas entre los reformadores de la etapa gregoriana, a mediados del siglo XI.

30. En muchas ocasiones, el propietario de un beneficio, que lo adquiría de por vida, podía servirlo por otro, que atendía sus obligaciones a cambio de parte de las rentas. Junto a los beneficios vitalicios o perpetuos, de los que no podían ser desposeídos salvo por causa grave, hubo otros temporales, también llamados manuales, nutuales o amovibles, de los que podían ser desposeídos, los titulares, por aquellos les nombraban ad nutum, libremente. Junto a ellos, existieron los beneficios honorarios, por los que no se recibían otras rentas que el reconocimiento social del propietario. 


\section{b) Las capellanías y las iglesias propias en la reforma carolingia}

Entre los beneficios erigidos para un servicio de ciertos intereses particulares o impropios, destacaron las capellanías fundadas para el servicio de un colegio o para cumplir ciertas mandas piadosas ${ }^{31}$. Entre estos últimos, existieron los préstamos, prestamillos y prestameras, que se surtían de las rentas de los diezmos para la manutención, por ejemplo, de profesores universitarios. Entre los préstamos, estaban las quintillas, las sextas, las novenas y las dozabas, según participaran de una quinta, sexta, novena o doceava parte de las tercias decimales de las iglesias.

En origen, se trató de ciertas fundaciones perpetuas por las que una persona, en vida o por testamento, segregaba de su patrimonio ciertos bienes con los que creaba un vínculo destinado a la manutención o congrua sustentación de un clérigo. Por ciertas cláusulas fundacionales, se obligaba a celebrar al capellán, por el alma del fundador o de los suyos, ciertas misas o cargas litúrgicas, de las que se llevaba un control exhaustivo. El concepto de capellanía procedía del hecho de que estas fundaciones, normalmente, eran erigidas en capillas tanto de iglesias catedrales o parroquiales como devocionales de los palacios y castillos o de las ermitas y santuarios de las distintas corporaciones eclesiales o profesionales ${ }^{32}$.

Si las capellanías eran instituidas por el ordinario, como verdaderos beneficios, se llamaban eclesiásticas. El obispo, normalmente, dotaba cierto oficio con bienes y efectuaba la colación, de donde le vino el nombre de capellanías colativas. A veces lo hacía a través de un patronato eclesiástico particular, unido a cierta iglesia, como las vinculadas a un cabildo. Otras, además del patronato activo, por el que el prelado nombraba al capellán, vinculaba las capellanías a ciertas condiciones familiares, como patronato pasivo, por las que se exigía que el designado fuera de su misma sangre o naturaleza.

También hubo capellanías laicales o mercenarias, en las que solo se exigía la aceptación del ordinario, que vigilaba para que se cumplieran las mandas previstas en los decretos de fundación. Se equipararon a los patronatos de laicos en los que los bienes raíces permanecían vinculados al fundador, de

31. M. Teruel Gregorio de Tejada, Vocabulario básico..., 63-69.

32. Entre estas destacaron las capellanías reales, erigidas en capillas reales, atendidas por capellanes mayores o reales, que ejercían también en otros templos parroquiales o catedralicios, o en capillas monásticas del Real Patronato. Se trataba de la extensión de la única capilla real o palatina, erigida para el servicio espiritual del rey o sus domésticos en el mismo palacio real, incluido el de Aquisgrán. En sus avances sobre los territorios reconquistados, o en diversos lugares de su jurisdicción, los reyes erigían este tipo de capillas y capellanías para que los sacerdotes velaran por el bien del monarca, del reino y de sus familiares, vivos y difuntos. 
donde procedían ciertas rentas para dotar el beneficio ${ }^{33}$. En este orden, también existieron los legados píos, en los que se entregaban ciertos bienes para una obra de caridad; y las memorias de misas, normalmente asociadas a los aniversarios de los difuntos. En muchos casos, los laicos se creyeron con el derecho de establecer quién debía cumplir las cargas.

La preocupación por la muerte y los tintes grotescos con que se ilustró la teología sobre el purgatorio llevó a muchos fieles a elaborar una cierta economía del cielo por la que se interpretaba que las mandas piadosas, las memorias de misas, los legados píos y la fundación de capellanías que ofrecieran, perpetuos, aniversarios y misas por su alma, podían garantizar la gloria y el perdón de los pecados de una vida desordenada y licenciosa, poco afecta a los principios de la moral cristiana.

Durante el siglo IX, se amplió el concepto de capellanía. El estadio más complejo fue el de la iglesia propia o de fundación privada. En ella, un patrono laico, propietario de una iglesia, nombraba al sacerdote que debía servirla. El mismo patrono sostenía económicamente al ministro y garantizaba la conservación de la fábrica y la provisión de los fondos necesarios para el culto, fundamentalmente para el sufragio por los difuntos y las misas. En las iglesias propias, el patrono se hizo detentador de ciertos derechos, como el cobro de los diezmos, el uso del espacio como panteón familiar y la exhibición, a veces ostentosa, de sus blasones heráldicos.

De muchas de estas iglesias propias, prohibidas por los agentes de la reforma gregoriana en el siglo XI, surgieron también, en la Baja Edad Media, algunos de los patronatos de laicos y muchas de las capellanías asociadas a las distintas iglesias, que fueron asumidas después por la autoridad eclesiástica.

\section{CONCLUSIÓN}

El concepto de permanens renovatio define de una manera propia, junto a las demás instituciones de la Iglesia, el ejercicio del ministerio sacerdotal a lo largo de la historia. Esta consideración no podía escapar a los planes centralizadores de Carlomagno, empeñado en hacer del clero secular un instrumento regio para la renovación de sus propias instituciones políticas y sociales ${ }^{34}$.

33. V. Bo, Storia della parrochia ..., 158-177.

34. C. Dawson, La religión y el origen de la cultura occidental, Madrid 1995; J. Paul, La Iglesia y la cultura en Occidente (siglos IX al XII), 2 vols. Barcelona 1988. En la mente de muchos reformadores resonó de una forma particular aquella lacónica expresión sobre la primera comunidad: «Perseveraban en la enseñanza de los apóstoles, en la comunión, en la fracción del pan y en las oraciones» (Hch 2,42); y también: «El grupo de los creyentes tenía 
Lo cierto es que la historia del clero después de la reforma carolingia tuvo una existencia verdaderamente compleja. Se podría decir que, como conclusión inesperada, se produjo la paradoja de la dignidad: el reconocimiento de la alta dignidad de la consagración sacerdotal convirtió a los ministros del culto en servidores de la eucaristía. Pero el sentido sacrificial, el servicio del altar y la atención pastoral a la comunidad, se pervirtió por la exigencia secular y el abuso de los príncipes.

La voluntad de Carlomagno y de su hijo Ludovico Pío para el clero se concretó en planes de reforma generalizados, impuestos con energía desde su consagración como rey de los francos, el año 768, hasta el tratado de Verdún, que puso fin a la guerra civil y dividió Europa entre los hijos del Emperador. La voluntad de asegurar una formación compleja en las artes y las ciencias sagradas, la exigencia de vinculación a los territorios diocesanos mediante la emisión de la promesa de obediencia al ordinario, así como el establecimiento del beneficio para la congrua sustentación de los ministerios sagrados permitió, durante décadas, una digna existencia del clero. No cabe duda de que los emperadores carolingios imaginaron un sacerdocio bien formado al servicio de su proyecto de renovación cultural y de elevación de la exigencia moral de la sociedad europea.

La pretendida vinculación del clero al desarrollo geopolítico del Imperio Carolingio, paradójicamente, jugó en contra de la reforma. La ruptura que se estableció a lo largo del siglo VIII entre el ministro y su comunidad, la creciente consideración de que la consagración confería a los ministros la potestas sacra más allá de la relación con la propia iglesia, en definitiva, la dignificación del sacerdocio en sí frente al pro eis anterior tuvo una consecuencia singularmente trágica en el momento en que se consumó la fragmentación del territorio en incontables jurisdicciones menores y los ministros quedaron atrapados en los feudos temporales tuyos titulares los emplearon, impropios, para asegurarse los dones sobrenaturales.

El sacerdocio ministerial se concibió entonces como un factor de santificación ex opere operato ajeno a la comunidad y a la vida de la Iglesia. La dinámica de división de la jurisdicción que se consumó después del tratado de Verdún, con un breve paréntesis durante el reinado de Carlos el Gordo (881-888), hizo que cada reyezuelo, duque, conde, marqués, y toda suerte de señores menores tuvieran a su disposición clérigos consagrados para ofrecer

un solo corazón y una sola alma: nadie llamaba suyo propio nada de lo que tenía, pues lo poseían todo en común» (Hch 4,32). La interpretación de esta síntesis sobre la comunidad apostólica ha llevado, a lo largo de los siglos, a una verdadera pléyade de manifestaciones de vida tanto religiosa como laical y, en lo que a este trabajo se refiere, también clerical. 
el sacrificio en memoria de sus difuntos que, al terminar la celebración, para la que escasamente llegaban preparados, podrían continuar con las labores agrícolas encomendadas a los demás trabajadores del feudo. El proyecto cultural de Alcuino de York pronto se diluyó entre las necesidades materiales de los enseñoreados terratenientes ${ }^{35}$.

La situación se arrastró durante todo el siglo X y la primera mitad del $\mathrm{XI}^{36}$. La reforma gregoriana, después del pontificado de León IX (1049-1054) afrontó, definitivamente, la libertad de la Iglesia que solo la orden benedictina de Cluny había conseguido años atrás para la vida regular. La crítica a los planes de san Crodegango, al que se le acusaba de haber permitido al clero la retención individual de los frutos y, por tanto, haber avivado la apetencia beneficial, no hizo justicia a su proyecto de santificación para los ministros sagrados. La injerencia laica en las provisiones había llevado, durante los siglos X y XI al naufragio de una renovación que se auguraba feliz. La libertad de la Iglesia fue la condición, después del pontificado de san Gregorio VII (1073-1085), para la definitiva implantación de los planes de reforma de la vida de los ministros sagrados ${ }^{37}$.

35. P. Martín Prieto, Historia del pensamiento medieval: filosofia y teología, Madrid 2016; P. Vignaux, El pensamiento en la Edad Media, Madrid 1999. D. Borobio García, Ministerio sacerdotal. Ministerios laicales, Bilbao 1982, 198-203, desarrolla algunos rasgos con los que delimita el ministerio sacerdotal después del siglo VIII: 1. Privatización del ministerio. «El ministerio pierde, en parte, su referencia a la comunidad, se absolutiza la ordenación, se multiplican los clérigos bajo un protector por el hecho de que la cheirothesia ha sido realizada conforme a las prescripciones de los libros litúrgicos oficialmente en vigor»; 2. Sacerdotalización y ritualización. «Se justifica la ordenación de presbíteros cuya única tarea es celebrar la misa (...) El servicio de la Palabra es relegado, de hecho, a un segundo plano»; 3. Finalización en la eucaristía. «Los presbíteros son ordenados, cada vez más, no al servicio de una comunidad, sino principal y casi exclusivamente para celebrar la eucaristía que, a su vez, viene a ser la misa privada»; 4. Feudalización del ministerio. «Bajo la idea del Sacro Imperio Romano, los obispos se convierten en príncipes eclesiásticos frente a los príncipes seculares en una estructuración feudal de la sociedad»; 5. La fragmentación de la sociedad y de la jurisdicción, lo que hace que docenas de clérigos rurales llenen las aldeas, sometidos a la voluntad arbitraria de los señores locales; 6. Dogmatización sacramental. En la misma línea interpretativa: E. Castellucci, Il ministero ordinato, Brescia 2002, 149-150. Según este autor, se acrecienta la concepción mágica del ministerio durante los siglos X y XI. El presbítero es un ser mágico porque convierte el pan y el vino en el Cuerpo y Sangre de Cristo. El acceso inmediato a la eucaristía iguala el ministerio de presbíteros y obispos. El paso a la pura y simple identificación sacramental es ya entonces muy pequeño.

36. D. Barthélemy, El año mil y la paz de Dios. La Iglesia y la sociedad feudal, Granada 2005; A. Vauchez, La espiritualidad del Occidente medieval (siglos VIII-XII), Madrid ${ }^{3} 2001$.

37. H. E. J. Cowdrey, Pope Gregory VII, 1073-1085, Oxford 1998; S. Gouguenheim, La Réforme Grègorienne. De la lutte pour le sacré à la sécularisation du monde, Paris 2010. 


\section{BIBLIOGRAFÍA CITADA}

Arnau-García, R., Orden y ministerios, Madrid 1995.

Ayala Martínez, C., El pontificado en la Edad Media, Madrid 2016.

Baron, A.- Pietras, H. (eds.), Acta synodalia. Documentos sinodales desde el año 50 hasta el 381, Madrid 2016.

Barthélemy, D., El año mil y la paz de Dios. La Iglesia y la sociedad feudal, Granada 2005.

Bo, V., Storia della parrochia. I secoli dell'infanzia (sec. VI-XI), Roma 1990.

Bonnassie, P., Le clergé rural dans l'Europe médiévale et moderne, Toulouse 1995.

Borobio García, D., Ministerio sacerdotal. Ministerios laicales, Bilbao 1982.

Calvo Gómez, J. A., La vida común del clero medieval. Origen y expansión de los canónigos regulares, Madrid 2016.

-El clero y los religiosos en la Edad Media, Madrid 2017.

Claramunt, S.- Portela, E.- González, M.- Mitre, E., Historia de la Edad Media, Barcelona 2010.

Collins, R., La Europa de la Alta Edad Media, 300-1000, Madrid 2000.

Constable, G., Monks, Hermits and Crusaders in medieval Europe, London 1988.

Contamine, P. La economía medieval, Madrid 2000.

Contreni, J. J., «Learning for God: Education in the Carolingian Age», The Journal of Medieval Latin 24 (2014) 89-129.

Cowdrey, H. E. J., Pope Gregory VII, 1073-1085, Oxford 1998.

Dawson, C., La religión y el origen de la cultura occidental, Madrid 1995.

Dhondt, J., La Alta Edad Media, Madrid 1993.

Folliard, D., «La reforma carolingia: a la unidad por la uniformidad», Concilium. Revista internacional de Teología 164 (1981) 72-79.

Foschi, F., «La regula canonicorum di Crodegango di Metz: alcuni problemi linguistici e di metodo», en: C. Arias Abellán (ed.), Latin vulgaire-latin tardif VII: Actes du VII Colloque international sur le latin vulgaire et tardif, (Sevilla, 2-6 septembre, 2003), Sevilla 2006, 273-284.

-«La formularità della lingua di Crodegango di Metz (742-766) e dei documenti del suo tempo», en: R. Wright, Latin vulgaire-latin tardif VIII. Actes du VIII Colloque international sur le latin vulgaire et tardif, Oxford, 6-9 septembre, 2006, Hildelheim 2008, 482-491.

Fransen, P. F. (ed.), Authority in the Church, Leuven 1983.

García de Cortázar y Ruiz de Aguirre, J. A., Historia general de la Alta Edad Media, Madrid 1984.

-Historia religiosa del Occidente medieval (Años 313-1464), Madrid 2012. 
García Macías, A., «Amalario de Metz (775-859)», Pastoral litúrgica: documentación información 318-319 (2010) 409-414.

Gaudemet, J., «La vie paroisseale en Occident au Moyen Âge et dans les temps modernes, en les communautés rurales», Recueils de la Société Jean Bodin 43 (1984) 64-86.

Giroud, C., L'ordre des chanoines réguliers de saint-Augustin et ses diverses formes de régime interne. Essai de synthèse historico-juridique, Martigny 1961.

Gouguenheim, S., La Réforme Grègorienne. De la lutte pour le sacré à la sécularisation du monde, Paris 2010.

Halphen, L., Charlemagne et l'Empire Carolingen, Paris 1947.

Hoyo Calleja, J. del- Gazapo Andrade, B., Anales del Imperio Carolingio (800-843), Madrid 1997.

Ivorra Robla, A. V., Los sentidos de la liturgia en Amalario de Metz, León 2007. - «A propósito de la palabra según Amalario de Metz», Toletana. Cuestiones de Teología e Historia 19 (2008) 75-87.

Kotzula, S., Der Priesterrat. Ekklesiologische prinzipien und Kanonistische verwirklichung, Leipzig 1983.

Mansi, G. D., Sacrorum comciliorum nova et amplisima collectio, 31 vols. Florencia-Venecia 1759-1798.

Martín Prieto, P., Historia del pensamiento medieval: filosofía y teología, Madrid 2016.

Miranda García, F., «Autores carolingios en los códices hispanos (siglos IXXI). Un ensayo de interpretación», Studia historica. Historia medieval 33 (2015) 25-50.

Mitre Fernández, E. La Iglesia en la Edad Media, Madrid 2003.

-Una primera Europa. Romanos, cristianos y germanos (400-1000), Madrid 2009.

Montanelli, I., Historia de la Edad Media, Barcelona 2004.

Nieto Soria, J. M. (coord.), Europa en la Edad Media, Madrid 2006.

O'Malley, J., Historia de los papas. Desde Pedro hasta hoy, Santander 2011.

Palanque, J. R., De Constantino a Carlomagno. A través del caos bárbaro, Andorra 1961.

Paul, J., La Iglesia y la cultura en Occidente (siglos IX al XII), 2 vols. Barcelona 1988.

-El cristianismo occidental en la Edad Media. Siglos IV-XV, Valencia 2014. Pelt, J. B., Études sur la cathédrale de Metz I. La liturgie, Metz 1937.

Phelan, O. M., «New Insights, Old texts, Clerical formation and the Carolingian Renewal in Hrabanus Maurus», Traditio: Studies in Ancient and Medieval History, Thought, and Religion 71 (2016) 63-89. 
Rincón-Pérez, T., El orden de los clérigos o ministros sagrados, Pamplona 2009.

Rodríguez de la Peña, M. A., «Alcuino de York, ideólogo del 'Imperium christianum': el análisis político en el Renacimiento Carolingio», en P. Sánchez Garrido- C. Martínez Sicluna y Sepúlveda, Historia del análisis político, Madrid 2011, 175-188.

Sánchez Prieto, A. B., «Rabano Mauro, Sobre la educación de los clérigos (De institutione clericorum): alcance y penetración de la escuela carolingia», Anuario de Historia de la Iglesia 24 (2015) 488-496.

-«Reorganización política, reforma religiosa, renacimiento cultural. El legado carolingio a la identidad de Europa», en: J. Peña González- M. A. Rodríguez de la Peña (eds.), Carlomagno y la civilización carolingia: Estudios conmemorativos en el 1200 aniversario (814-2014), Madrid 2014, 89-124.

- «The transmission and reception of the De institutione clericorum», Millars: Espai i Historia 46/1 (2019) 17-40.

Solarana Cabezuela, M. I., «La escuela palatina de Aquisgrán: Alcuino de York», Revista de Arqueología 27/302 (2006) 47-55.

Teruel Gregorio de Tejada, M., Vocabulario básico de Historia de la Iglesia, Barcelona 1993.

Valdeón Baruque, J., La Alta Edad Media, Madrid 2005.

Vauchez, A., La espiritualidad del Occidente medieval (siglos VIII-XII), Madrid $^{3} 2001$.

Vignaux, P., El pensamiento en la Edad Media, Madrid 1999. 